\title{
Wear Resistance of Metallic Orthopedic Implants - Mini Review
}

\author{
SJ Gobbi* and VJ Gobbi* \\ Faculty of Technology, Brazil
}

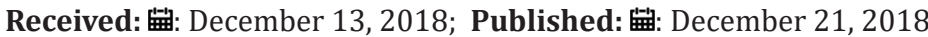

*Corresponding author: SJ Gobbi and VJ Gobbi, Faculty of Technology, Brazil

\begin{abstract}
Over the last fifty years, the science of biomaterials has investigated different types of metallic biomaterials and their applications to replace or restore the function of compromised or degenerate tissues. The field of biomaterials showed rapid growth to maintain the demands of population aging. However, implants are expected to work much longer or until lifetime without failure or revision surgery. Wear on metallic biomaterials is mainly present in artificial joints. Wear characteristics are a very important aspect of the performance of biomedical alloys, where failures generally occur due to excessive wear of the components. An increase in wear resistance of the implant will prevent the generation of wear debris and an adverse cellular response. The present work aims to describe the consequences of wear on orthopedic implants.
\end{abstract}

Keywords: Wear; Metallic Biomaterial; Artificial joints

\section{Introduction}

Of all the biomedical alloys are required the satisfaction of several criteria, such as adequate strength, high resistance to corrosion, bioadhesion, biofunctionality, biocompatibility, high wear resistance, and low friction [1,2]. As a result of the mixed lubrication regime, wear occurs in the articulation of artificial joints. Accumulation of wear debris can produce an adverse cellular response leading to inflammation, release of harmful enzymes, osteolysis, infection, implant loosening and pain [3]. The wear of the components in contact with artificial joints is affected by several factors, such as level of the patient's activities, body weight, quality and quantity of synovial fluid, level and type of stresses on articulating surfaces, material properties, geometry and dimension, imperfections of components and surgical techniques and accuracy [4].

The representative metallic biomaterials used are stainless steels, cobalt (Co) - chromium (Cr) alloys, and titanium (Ti) and its alloys [5]. Research and development of new titanium alloys free of toxic elements and with low Young's modulus are being carried out in order to reduce the mechanical incompatibility of the implant in relation to the bone, thus avoiding the phenomenon of stress shielding $[2,5]$. The objective of this work is to describe the importance of the wear performance of metallic biomaterials and the methods reported as promising in increasing wear resistance.

\section{Wear on Orthopedic Implants}

High wear resistance is a key property for determining the longevity of joint implants in the human body. Eventual loosening of the implant due to osteolysis has been attributed to local inflammatory responses to wear [6]. The association between wear rate and osteolysis in total hip orthoplasty (replacement of the arthroscopic or deficient joint by a prosthesis) was performed by Dumbleton et al. [7]. They conclude that the incidence of osteolysis increases as the wear rate increases. Also point to osteolysis as a consequence of the cellular response to wear debris, being considered as the limitation of the long duration of the prosthesis life. So, wear produces biologically active rejects that stimulate an inflammatory response and also cause osteolysis and the shape of the prosthesis surfaces undergo changes due to wear and tear that affect their normal function [7-9]. The low wear resistance leading to the release of wear debris from the implant into the surrounding tissue results in bone resorption, leading to loosening of the implant and to various reactions of the tissue in which it is deposited [8].

Total replacement by loosening of joints made of metal head and polymer cup has been reported many times and $10-20 \%$ of joints need to be replaced within 15-20 years. Knee replacement surgery is performed on more than 2.5 million people in the US alone per 
year, followed by total replacement of hip agitation with more than 3.5 million and about 7 million spinal fusions [8]. Post-mortem studies of patients receiving total hip or knee replacements have shown that the accumulation of wear particles in the liver, spleen or abdominal lymph nodes is a common occurrence in patients. It is pointed out that high concentrations of metal were found in tissue removed from the region around titanium alloy prostheses [8]. Compared to stainless steel and cobalt alloys, titanium alloys have proven to be superior in terms of biocompatibility [9], besides presenting lower Young's modulus, better resistance to corrosion and high specific strength $[5,9]$. These are some of the factors that make titanium and its alloys the most promising biomaterials for implants [5,8-10].

The Ti-6Al-4V alloy (Young's modulus of $110 \mathrm{GPa}$ ) is the alloy most commonly used as an implant material, however the development of low modulus Ti alloys for biomedical applications has evolved in recent years $[5,10]$. The bone tissue presents a modulus of 10-40 $\mathrm{GPa}$, leading to a mechanical incompatibility in relation to the metallic implant, a phenomenon called a stress shielding that potentially can cause bone resorption and eventual failure of the implant [2,8-10]. These new titanium alloys are of type $\beta$ composed of elements $\mathrm{Fe}, \mathrm{Cr}, \mathrm{Zr}, \mathrm{Mn}, \mathrm{Tn}, \mathrm{Nb}$, such as: $\mathrm{Ti}-12 \mathrm{Cr}$, Ti-13Nb-13Zr, Ti-Cr-Sn-Zr,Ti-Mn-Fe [5,10]. However, despite good mechanical properties, Ti and its alloys exhibit low tribological performance, such as a high and unstable coefficient of friction, severe adhesive wear and low abrasive wear resistance, which limits its application $[4,11]$. (He et al., Falcade et al., Zhang et al., Wang et al.). The adequate surface treatment expands the use of titanium and its alloys in the biomedical areas, being one of the most effective methods to improve the wear resistance of the titanium alloys $[3,5,12]$. Surface hardening is one of the most effective methods to improve the wear resistance of titanium alloys such as nitriding techniques and PVD/CVD coatings [12].

\section{Final Considerations}

The above discussion illustrates that the wear resistance of the material plays a significant role in the proper functioning of the metallic biomaterial. High wear resistance avoids loosening of the implant and reactions in the tissue in which it is deposited, improving the patient's quality of life. Altering the nature of the surface, ie applying the concepts of surface engineering are reported as the most effective methods to increase tribological properties.

\section{References}

1. Patel NR, Gohil PP (2012) A review on biomaterials: Scope. Application s \& human anatomy significance. International Journal of Emerging Technology and Advanced Engineering 2(4): 91-101.

2. Yilmazer H, Niinomi M, Nakai $M$, Cho $K$, Hieda J, et al. (2013) Mechanical properties of a medical $\beta$-type titanium alloy with specific microstructural evolution through high-pressure torsion. Materials Science and Engineering C 33(5): 2499-2507.

3. Li SJ, Yang R, Li, Hao YL, Cui YY, et al. (2004) Wear 257: 869-876.

4. Ching HA, Choudhury D, Nine MJ, Osman NAA (2015) Effects of surface coating on reducing friction and wear of orthopaedic implants-Review. Science and Technology of Advanced Materials 15: 014402.

5. Niinomi M, Nakai M, Hieda J (2012) Development of new metallic alloys for biomedical applications. Acta Biomaterialia 8(11): 3888-3903.

6. Hallab N, Jacobs JJ (2009) Biologic effects of implant debris. Bulletin of the NYU Hospital for Joint Diseases 67(2): 182-188.

7. Dumbleton J, Manley M, Edidin A (2002) A Literature Review of the Association Between Wear Rate and Osteolysis in Total Hip Arthroplasty. The Journal of Arthroplasty 17(5): 649-661.

8. Geetha M, Singh AK, Asokamani R, Gogia AK (2009) Ti based biomaterials, the ultimate choice for orthopaedic implants- A review. Progress in Materials Science 54(3): 397-425.

9. Chen Q Thouas GA (2015) Metallic implant biomaterials. Materials Science and Engineering R 87: 1-57.

10. Wang J, Ma J, Huang W, Wang L, He H, et al. (2017) The investigation of the structures and tribological properties of F-DLC coatings deposited on Ti-6Al-4V alloys. Surface and Coatings Technology 316: 22-29.

11. Nakai M, Niinomi M, Zhao X, Zhao X (2011) Self-adjustment of Young's modulus in biomedical titanium alloys during orthopaedic operation. Materials Letters 65(4): 688-690.

12. Niinomi M (2008) Mechanical biocompatibilities of titanium alloys for biomedical applications. Journal of the Mechanical Behavior of Biomedical Materials 1(1): 30-42.

\section{ISSN: 2574-1241}

DOI: 10.26717/BJSTR.2018.12.002266

SJ Gobbi, VJ Gobbi. Biomed J Sci \& Tech Res

(C) (i) This work is licensed under Creative Commons Attribution 4.0 License

Submission Link: https://biomedres.us/submit-manuscript.php

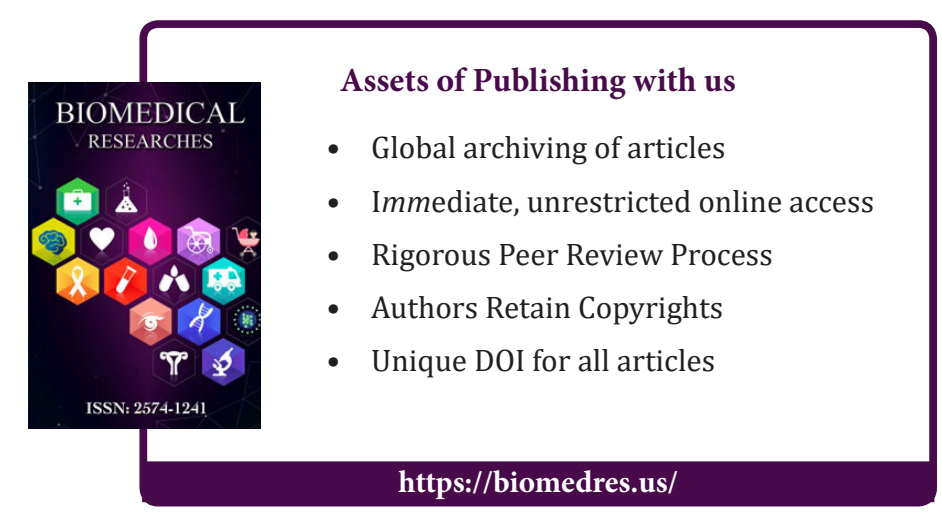

